\title{
Association between Inspirational Leadership Traits and Job Commitment among Secondary School Teachers in a Remote District of Uganda
}

\author{
Christine Rose Akurut $^{1} \&$ Aloysius Rukundo ${ }^{2}$ \\ ${ }^{1,2}$ Department of Educational Foundations and Psychology, Mbarara University of Science and \\ Technology, Uganda \\ Correspondence: Aloysius Rukundo, Mbarara University of Science and Technology, Uganda. \\ Email: arukundo@must.ac.ug
}

DOI: $10.53103 /$ cjess.v1i1.4

\begin{abstract}
Aim: Establishing the association between the dimensions of perceived inspirational leadership traits and job commitment among secondary school teachers.

Methods: It was cross-sectional, with quantitative approach. A questionnaire was used to obtain data from 250 teachers. Linear regressions in SPSS were used to determine the association between study variables.

Results: Combined commitment was significantly associated with flexibility and listening, but not with responsibility. After separation of the commitment dimensions, normative commitment was associated with flexibility, listening, and responsibility. However affective commitment was associated with flexibility and listening, while continuance commitment was associated with only flexibility. All the three leadership traits accounted for $21.7 \%$ of the variance in combined commitment.

Conclusion: Inspirational leadership is crucial in normative commitment of teachers towards their job. Further, leadership traits could serve to motivate teachers to engage in activities, beyond the job requirements, in a way that makes them perform better in their obligations.
\end{abstract}

Keywords: Leadership Traits, Inspiration, Commitment, Teachers, Secondary Schools, Uganda

\section{Introduction}

There is a rising concern, today, regarding attracting job affection and commitment among employees (Mercurio, 2015). Schools are not an exception in the emerging concern regarding commitment, especially of teachers towards their job. Globally, teachers are considered as prime movers in implementing curriculum and instruction (Duze, 2012). In this respect, teacher-commitment plays a vital role in achieving quality education and spurs school outputs (Banjarnahor et al., 2018; Achua \& Lussier, 2013) Thus, the success of education is routed on inspirational leadership traits and better-quality job commitment (Leithwood \& Sun 2012; Huang et al., 2014). 
Inspirational leadership assumes responsibility, listening and flexibility as traits as perceived by other teachers to be inherent among their leaders (Bain, 2017; Boseman, 2008). Principally, inspirational leaders are not driven by personal success, but rather inspire their followers to get them to another level of flourishing and satisfying organizational goals (Bain, 2017; Goleman \& Boyatzis, 2008). Job commitment denotes a bond between an individual (the employee) and the institution (the employer), and the degree to which a person identifies psychologically with his/her work due to lived experience (Chen \& Aryee, 2007; Ćulibrk et al., 2018; Oyewobi et al., 2012).

Accordingly, when school leadership inspires teacher-commitment, the overall outcome drives school academic performance to the right direction (Bain, 2017; Goleman \& Boyatzis, 2008). Perceptibly, managers could lead subordinates effectively when they endeavor to inculcate a sense of commitment and the desire to accomplish organizational goals (Brown \& Owusu, 2014). So, school leaders have the responsibility of instilling commitment, teamwork and building trust among staff and increase overall school effectiveness (Kashagate, 2013).

Indeed, teachers who are dedicated to developing their service delivery could be able to dedicate all their effort to the job (Oyewobi et al., 2012). In that sense, job commitment among teachers could be closely associated with teachers' work performance and their ability to innovate and incorporate new ideas into their own practice (Kashagate, 2013). However, previous school inspection reports in some of the remotest area of Uganda pointed to lack of commitment among secondary school teachers. To this end, this study sought to explore the association between perceived inspirational leadership traits and teachers' job commitment. In relation to the study aim above, a question is asked: Is there a statistically significant association between perceived inspirational leadership traits and job commitment among secondary school teachers?

Inspirational leadership is frequently associated with dialogue, transparency and positive energy. Thus, inspirational leadership does not only demonstrate respect and fair behavior, but also provides energy, positivity and motivation for their followers (Jabeen et al., 2020; Riivari \& Lämsaä, 2014). In that sense, employee well-being and commitment to the job depends not only on the physical work context, but also the psychosocial work environment in which inspirational leaders play a key role (Gilbreath \& Benson, 2004; Jabeen et al., 2020). So, teaching staff in schools require a more positive attitude from their leaders, to get them committed to their job through teamwork (Murphy, 2007). It is thought that dedication of workers is an essential apparatus for effectively enhancing the execution of the mandate of institutions (Banjarnahor et al., 2018; Chen \& Aryee, 2007). This, therefore indicates that inspirational leadership traits are essential elements for employee well-being and productivity (Alvino, 2014; Harris \& Kacmar, 2006; Mercurio, 2015; Stander \& Rothmann, 2009). Indeed, inspirational leadership traits serve to motivate teachers to engage in activities that are beyond the job requirements, in a way that makes 
them perform better in their obligations.

Inspirational leadership influences job commitment in terms of morale, work relations, perception of tasks, performance levels, and amount of time spent on station and submission to the top management (Bain, 2017; Stander \& Rothmann, 2009). However, these aspects may be influenced in a negative way when leadership is non-inspirational. Consequently, workers who are not committed to their organization are more likely to put less effort in the duties as compared to those with high levels of commitment (Akinwale, 2019; Maxwell, 2007; Mueller et al., 1992).

Job commitment is characterized by the presence of strong belief and reception of the objectives and values of the school, readiness to work hard and a strong desire to stay in teaching (He et al., 2019; Wang \& Bowling, 2016). Commitment is construed in three parts - affective, normative and continuance commitment (Meyer \& Allen, 1990; Meyer \& Allen, 1997a, 1997b). Continuance commitment is when employees are continually working for organization because they cannot bear the cost to leave the organization. In normative commitment, employees continually work for the organization because they feel their obligations to exist in the organization (Meyer \& Allen, 1990). Affective commitment is the identification and involvement of the individuals in achievement of organizational goals and objectives (Ellis \& Dick, 2003; Kiral \& Kacar, 2016).

Affective commitment could depend on emotional ties the employee develops with the organization through positive work experiences (Molenberghs et al., 2017; Kiral \& Kacar, 2016). Normative commitment is about perceived obligations towards the organization routed in the norms of reciprocity (Singh \& Singh, 2019). On the other hand, inspirational leaders influence commitment and loyalty towards organization by giving their actions a particular direction, building self-reliance and rousing their faith in the organization. Idealized influence makes the followers aware of their importance toward work and provokes keenness, thrill, emotional attachment and commitment toward common goal. All the definitions precipitate to influence, direction or persuasion of a person or a group to move in a given direction (Northhouse, 2012; Stander \& Rothmann, 2009). Head teachers lead and manage all aspects of the schools with an aim of improving the standards and performance of learners.

Susilo (2018) further expounds that inspirational leadership is the motivation and mobilization of others to undertake collective action in pursuit of a common goal. It includes controlling, directing and indeed all techniques and methods used by leaders to motivate subordinates to follow their instructions (Malik, Aftab \& Ahmad, 2018; Susilo, 2018). It is a procedure to influence the followers in order to achieve the desired goals and objectives of the organization (Khan, Ismail, Hussain, \& Alghazali, 2020; Mwamatandala \& Muneja, 2020).

The relationship between inspirational leadership and commitment among teachers is grounded in the traditional trait theory of leadership, advanced by Fleenor (2006). The 
trait theory looks at different traits from the perspective of individual leaders. According to Fleenor, such traits could denote physical and personality characteristics. The traits are said to determine the success of a leader, and how the leader impacts the sub-ordinates. It assumes that traits, which are relatively stable over time, produce patterns of behavior consistent across different situations (Mwamatandala \& Muneja, 2020). Traits such as flexibility, responsibility, and effective communication fall within the aspects of this theory (Bain, 2017). These traits, if possessed by a school leader, would in turn encourage teachers to have a good attitude to the school, therefore keeping them committed to their job (Susilo, 2018).

The trait approach is regarded as having its roots in the "Great Man" theory and focuses on innate traits possessed by school leaders (Northhouse, 2012). Different circumstances therefore call for different leadership traits. It posits that leadership is a relationship between people in a social setting. As such, relationships and situations could change. Evidence supports the position that leadership is not purely a situational occurrence, but more so connected to individual attributes (Northhouse, 2012). That approach to leadership is valid to the examination of leaders and the dominance they have on their sub-ordinates. Therefore, a leader's personality has predictable effects on team performance and job commitment. A leader must invest time and work in developing his or her intellect, which in turn generates inspiration towards job commitment (Mistry \& Hule, 2015; Pangarkar \& Kirkwood, 2013). This study, in consideration of earlier researchers' ideas regarding inspirational leadership traits and job commitment adopted the traditional trait theory to guide the conception and analysis of the concepts considered herein.

\section{Methodology}

\section{Design}

A cross-sectional design was used to measure variables. Quantitative data was collected owing to the fact that questionnaires generate statistical data and allow for an easy computation of descriptive statistics and variable correlations (Bailey, 2007).

\section{Settings}

The study was conducted in Ngora District, Eastern Uganda. Ngora borders Kumi district in the East, Serere district in the West, Soroti district in the North West, Katakwi district in the North and Pallisa district in the South.

\section{Population}

By the time of the study, Ngora district had 23 schools. Of these schools, 18 had 
opened after the first COVID-19 lockdown, while five had not. The target population in the 23 schools was 593 teachers and 470 in the 18 schools that were considered.

\section{Sampling}

All the 18 schools that had opened after the first COVID-19 lockdown were considered by census. Furthermore, all teachers in each of the considered schools that were present at the time of data collection were enrolled into the study. Two hundred fifty teachers completed the survey instrument, constituting 53.2\% of the teachers in schools that had opened.

\section{Instrument}

A self-administered questionnaire with closed-ended items was used for data collection. A questionnaire collects lots of information in a short period of time (Fraenkel \& Wallen, 1990). The questionnaire comprised three sections. In section A, sociodemographic background information of the participants was captured.

In section B, a 21-item scale (DeVellis, 2003) was used to measure inspirational leadership traits. The inspirational leadership scale was on a five-point Likert as strongly agree (5), agree (4), not sure (3), disagree (2) and strongly disagree (1). The scale has a validity and reliability indices of 0.83 and 0.85 respectively (DeVellis, 2003). It is particularly focused on subordinates' perceptions of their leaders' behavior, which made it appropriate for the current study. Employees were asked about their perception of their leader in as far as being inspirational was concerned.

In the third section, job commitment was measured on a five-point Likert scale (Meyer \& Allen, 1997a) as strongly agree (1), agree (2), not sure (3), disagree (4) and strongly disagree (5). This particular scale was chosen because of its apparent advantages. First, numerous studies have reported acceptable internal consistency reliabilities for its three sub-scales. For instance, Fields (2012) found that the Cronbach's alpha coefficients ranged from 0.77 to 0.88 for affective commitment, 0.65 to 0.86 for normative commitment and 0.69 to 0.84 for continuance commitment.

\section{Procedure for Data Collection}

Ethical clearance was first sought from the Institutional Ethical Review Committee of Mbarara University of Science and Technology, protocol number 16/11-19. Further clearance was sought from the Chief Administrative officer and the District Inspector of Schools to carry out the study in the various secondary schools in the District. Permission was then sought from the head teachers to enable access to the study participants. Participants were first briefed regarding the study aim and their rights when participating in the study. Also, they were briefed about following the COVID-19 Standard Operating 
Procedures to follow. Their consent was sought by them accepting to sign the consent form first which later was immediately retrieved from them. After consenting, each participant was handed a copy of the study instrument to fill confidentially. Filled-in copies were then dropped in a box placed in an appropriate place. Participants were thanked for their participation and then released.

\section{Data Management}

Feedback from the questionnaire, descriptive statistics and regressions among variables was analyzed using Statistical Package for Social Scientists (SPSS) version 20.0.

All items have a 5-point Likert type scale except for the items on demographics background for teachers. For the section on perceived inspirational leadership traits, items will have a 5-point Likert scale measured on 5 to 1 on which 5 scored Strongly Agree, 4 for Agree, 3 for Not Sure, 2 for Disagree and 1 for Strongly Disagree. Mean score for above 3 will indicate high Perceived Inspirational Leadership Traits and Mean score of below 3 will indicate less influence of Perceived Inspirational Leadership Traits on Job Commitment.

The last section on job commitment will be measured on 5 to 1 on which 5 scored Strongly Agree, 4 for Agree, 3 for Not Sure, 2 for Disagree and 1 for Strongly Disagree. The mean will be determined and items that will score above the mean of 3 and above will be rated as high job commitment. Items that will score a mean of less than 3 will be indicated as low job commitment.

\section{Data Analysis}

Descriptive statistics were used to describe the socio-demographic data of the study participants. To determine the association between perceived inspirational leadership traits and job commitment among secondary school teachers, correlation matrix and hierarchical linear regression coefficients were used.

\section{Findings}

The study aimed at finding out the association between perceived inspirational leadership traits and teachers' job commitment. Descriptive statistics were used in describing the sample characteristics. Inferential statistics were used in exploring the study objective. The analyses and their descriptions are included in the subsequent Tables and texts. 
Table 1: Demographic characteristics of participants $(\mathrm{N}=250)$

\begin{tabular}{|c|c|c|c|}
\hline Characteristics & & Frequency (n) & Percent \\
\hline \multirow{5}{*}{$\begin{array}{c}\text { Category of } \\
\text { Schools }\end{array}$} & Government aided & 163 & 65.2 \\
\hline & Private & 87 & 34.8 \\
\hline & Deputy Head teacher & 15 & 6.0 \\
\hline & Director of Studies & 13 & 5.2 \\
\hline & Head of Department & 46 & 18.4 \\
\hline \multirow[t]{4}{*}{ Designation } & Class teacher & 44 & 17.6 \\
\hline & Senior man teacher & 6 & 2.4 \\
\hline & Senior woman teacher & 6 & 2.4 \\
\hline & Ordinary teacher & 120 & 48.0 \\
\hline \multirow{3}{*}{ Sex of participant } & Male & 177 & 70.8 \\
\hline & Female & 73 & 29.2 \\
\hline & $19-28$ & 54 & 22.4 \\
\hline \multirow{4}{*}{ Age } & $29-38$ & 113 & 45.2 \\
\hline & $39-48$ & 64 & 25.6 \\
\hline & $49-59$ & 19 & 7.6 \\
\hline & Single & 66 & 26.4 \\
\hline \multirow[t]{2}{*}{ Marital Status } & Married & 181 & 72.4 \\
\hline & Others & 3 & 1.2 \\
\hline \multirow{4}{*}{$\begin{array}{c}\text { Academic } \\
\text { Qualification }\end{array}$} & Diploma & 56 & 22.4 \\
\hline & Degree & 179 & 71.6 \\
\hline & Master's Degree & 15 & 6.0 \\
\hline & $0-5$ years & 65 & 26.0 \\
\hline \multirow{3}{*}{$\begin{array}{l}\text { Experience in } \\
\text { teaching }\end{array}$} & $6-10$ years & 99 & 39.6 \\
\hline & $11-20$ years & 66 & 26.4 \\
\hline & $21 \&$ above & 20 & 8.0 \\
\hline \multirow{3}{*}{$\begin{array}{c}\text { Terms of } \\
\text { employment }\end{array}$} & Temporary & 13 & 5.2 \\
\hline & Permanent & 138 & 55.2 \\
\hline & Contract & 99 & 39.6 \\
\hline
\end{tabular}

In Table 1, most participants were from government aided schools, 163 (65. 2\%). Majority were teachers without other responsibilities (48.0\%), and males, 177 (70.8\%). Most of the respondents were of ages between 29 and 38 years, 113(45.2\%) and (72.4\%) were married. Majority of respondents constituted of degree holders as their highest level of education, 179(71.6\%), 56(22.4\%) had diploma. Over a quarter, 99 (39.6\%) had spent between 6-10 years in the teaching profession. Majority was employed on permanent basis, $138(55.2 \%)$. 
Table 2: Descriptive statistics for study variables

\begin{tabular}{cccccc}
\hline \multicolumn{2}{c}{ Variables } & Mean & SD & Median & IQR \\
\hline Perceived & Flexibility & 30.1 & 3.5 & 31.0 & $28.0-33.0$ \\
Inspirational & Listening & 26.5 & 3.6 & 27.0 & $24.8-29.0$ \\
Leadership & Responsibility & 29.1 & 3.6 & 30.0 & $27.0-31.0$ \\
\cline { 2 - 6 } & Overall & 85.7 & 9.3 & 88.0 & $80.0-93.0$ \\
\hline $\begin{array}{c}\text { Job } \\
\text { Commitment }\end{array}$ & $\begin{array}{c}\text { Affective } \\
\text { Commitment } \\
\text { Normative } \\
\text { Commitment } \\
\text { Continuance } \\
\text { Commitment }\end{array}$ & 27.4 & 3.9 & 27.0 & $24.0-30.0$ \\
\cline { 2 - 6 } & Overall & 80.0 & 3.4 & 26.0 & $24.0-27.0$ \\
\cline { 2 - 6 } & & 4.9 & 28.0 & $24.0-31.0$ \\
\hline
\end{tabular}

IQR: Inter Quartile Range; SD: Standard Deviation

Table 2 shows that of the perceived inspirational leadership traits, flexibility was the most reported $($ Mean $=30.1, \mathrm{SD}=3.5$, Median=31.0, IQR: 28.0-33.0). The least reported trait was listening (Mean $=26.5, \mathrm{SD}=3.6$; Median $=27.0$, IQR: 24.8-29.0). In relation to job commitment, normative commitment was the most reported (Mean $=27.5$, $\mathrm{SD}=3.4$, Median =30.0, IQR: 24.0-27.0). The least reported dimension of job commitment was continuance commitment $($ Mean $=25.1, \mathrm{SD}=4.9$; Median =28.0, IQR: 24.0-31.0).

\section{Association between Perceived Inspirational Leadership Traits and Job Commitment}

The main objective was to find out the association between perceived inspirational leadership traits and job commitment among secondary school teachers. In order to achieve the objective, a question was set: Is there a statistically significant association between perceived inspirational leadership traits and job commitment among secondary school teachers?

Correlation matrix and regression coefficients were used to answer the question above. Table 3 presents the correlation matrix of independent variable and dependent variable. 
Table 3: Correlations between inspirational leadership traits and job commitment

\begin{tabular}{|c|c|c|c|c|c|c|c|c|}
\hline Variables & 1 & 2 & 3 & 4 & 5 & 6 & 7 & 8 \\
\hline Job & 1 & & & & & & & \\
\hline \multicolumn{9}{|l|}{ Commitment } \\
\hline Affective & .628 & 1 & & & & & & \\
\hline Commitment & $* *$ & & & & & & & \\
\hline Continuance & .832 & $.267^{*}$ & 1 & & & & & \\
\hline Commitment & $* *$ & * & & & & & & \\
\hline Normative & .624 & .058 & .368 & 1 & & & & \\
\hline Commitment & $* *$ & & $* *$ & & & & & \\
\hline Flexibility & .433 & $.129^{*}$ & .276 & $.562 *$ & 1 & & & \\
\hline Listening & $\begin{array}{l}.438 \\
* *\end{array}$ & $\begin{array}{l}.176^{*} \\
*\end{array}$ & $\begin{array}{l}.266 \\
* *\end{array}$ & $\begin{array}{l}.532 * \\
*\end{array}$ & $\begin{array}{l}.694 * \\
*\end{array}$ & 1 & & \\
\hline Responsibility & $\begin{array}{l}.364 \\
* *\end{array}$ & .074 & $\begin{array}{l}.196 \\
* *\end{array}$ & $\begin{array}{l}.566^{*} \\
*\end{array}$ & $\begin{array}{l}.643 * \\
*\end{array}$ & $\begin{array}{l}.649 * \\
*\end{array}$ & 1 & \\
\hline Overall Traits & $\begin{array}{l}.468 \\
* *\end{array}$ & $.144^{*}$ & $\begin{array}{l}.279 \\
* *\end{array}$ & $\begin{array}{l}.629 * \\
*\end{array}$ & $\begin{array}{l}.882 * \\
*\end{array}$ & $\begin{array}{l}.889^{*} \\
*\end{array}$ & $\begin{array}{l}.870^{*} \\
*\end{array}$ & 1 \\
\hline
\end{tabular}

**. Correlation is significant at the $\mathrm{p} \leq .01$ level (2-tailed).

*. Correlation is significant at the $\mathrm{p} \leq .05$ level (2-tailed).

Table 3 shows that there was a statistically significant moderate positive association between overall perceived Inspirational Leadership Traits and Job Commitment among Secondary schools in Ngora District $(\mathrm{r}=.468, \mathrm{p}<.01)$. Specifically, the highest correlation was listening $(r=.438, \mathrm{p}<.01)$ followed by flexibility $(\mathrm{r}=.433, \mathrm{p}$ $<.01)$ and then responsibility $(\mathrm{r}=.364, \mathrm{p}<.01)$. Regression analyses were implemented in order to determine the extent to which job commitment can be predicted from perceived inspirational leadership traits.

Table 4: Regression Results for the association between perceived inspirational leadership traits and job commitment

\begin{tabular}{|c|c|c|c|c|c|c|c|}
\hline & & & Flex & List & Resp & $\mathrm{R} 2$ & \\
\hline & Variables & & & & & & Adj.R2 \\
\hline & Model & B & $1.09 *$ & & & & \\
\hline & 1 & & $* *$ & & & & \\
\hline 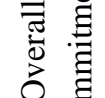 & & $\beta$ & $\begin{array}{c}0.433 \\
* * *\end{array}$ & ----------- & ---------- & 0.188 & 0.185 \\
\hline ن & $\begin{array}{c}\text { Model } \\
2\end{array}$ & B & $\begin{array}{c}0.629 \\
* * *\end{array}$ & $0.640^{* * *}$ & & & \\
\hline
\end{tabular}




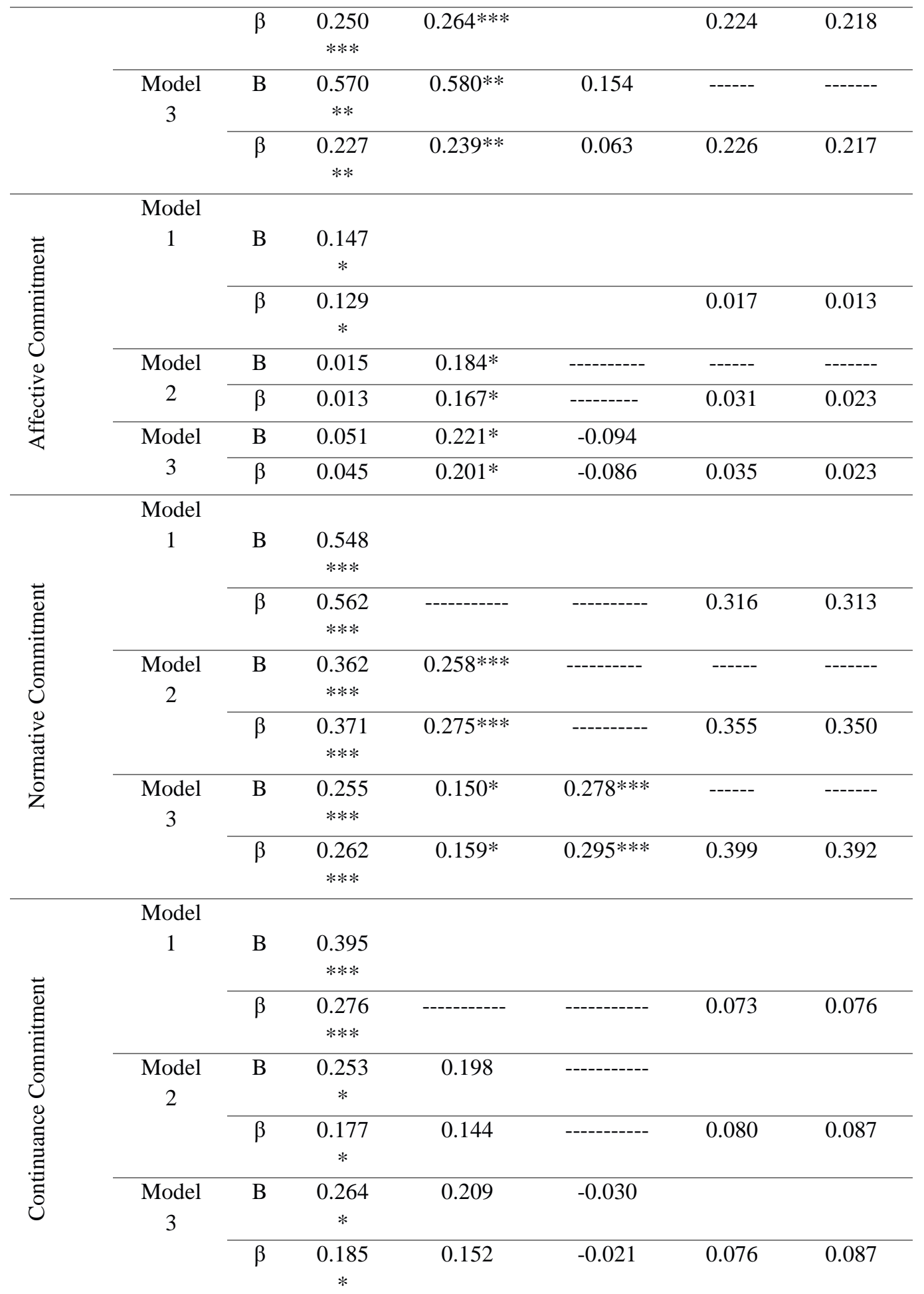

Note: $* p \leq 0.05 ; \quad * * p \leq .01 ; * * * p \leq .001$. Flex=flexibility; List=listening; Resp=responsibility 
It is observable in Table 4 that overall job commitment was significantly associated with two traits of job commitment, namely flexibility $(\beta=.433, \mathrm{p}<.001)$ and listening $(\beta=$ $.264, \mathrm{p}=.001)$. Responsibility was non-significantly associated with overall job commitment $\beta=.063, \mathrm{p}>.05 \mathrm{p}<0.05$ ). The associations were positive. However, flexibility explains $18.8 \%$ of the observed overall job commitment. Flexibility and listening together explain $21.8 \%$ of the observed overall job commitment, while all the dimensions of inspirational leadership traits account only for $21.7 \%$ of the observed job commitment. When the constructs of job commitment were separated, it was found that affective commitment was associated with flexibility $(\beta=.129, \mathrm{p}<.05)$, listening $(\beta=.167, \mathrm{p}=.05)$, but not with responsibility. However, normative commitment was associated with all the three categories of leadership traits - flexibility $(\beta=.562, \mathrm{p}<.001)$, listening $(\beta=.275$, $\mathrm{p}<.001)$ and responsibility $(\beta=.295, \mathrm{p}<.001)$. Continuance commitment was associated with only flexibility $(\beta=.276, \mathrm{p}<.001)$, but not with listening $(\beta=.144, \mathrm{p}>.05)$, or responsibility $(\beta=-.021, \mathrm{p}>.05)$. Noticeably, as compared to other variables, the continuance commitment registered lower coefficients in association with leadership traits.

\section{Discussion, Conclusions, and Recommendations}

The study aimed at establishing whether there was an association between perceived inspirational leadership traits and job commitment among secondary school teachers. To achieve the aim, linear regressions were used. The study found that combined job commitment was significantly associated only with flexibility and listening. In separate treatment of job commitment, normative commitment was associated with all the three traits of leadership. That, therefore indicates that inspirational leadership traits are essential elements for employee well-being and productivity (Banjarnahor et al., 2018). Nevertheless, affective commitment associated only with flexibility and listening. However, Continuance commitment was associated with flexibility only.

The findings regarding combined commitment associating with flexibility and listening seem to suggest that leaders could need flexibility and then listening to the teachers' concerns, rather than continuance, for the teachers to commit in all the three aspects affective, normative and continuance. It seems affective and continuance commitment could be predicted better by other aspects, probably emoluments, rather than leaders' traits. So, teachers' feeling of continually working for their schools could be more of the assessment of bearing the cost of leaving the school, rather than leaders' behaviors.

The findings regarding combined commitment associating with flexibility and listening may not be distant from the previous studies. In relative cohorts with the present study results, previous research shows that the three components of commitment affective, continuance and normative have quite different consequences for other work related behavior, such as attendance, performance of required duties and willingness to go above and beyond the call of duty (Meyer \& Allen 1991, 1997a, 1997b). Moreover, it was 
reported that employees who were pleased with their leaders and felt they were treated with respect, humor and appreciated by their leaders committed better to their organizations (Bushra et al., 2011).

In addition, combined commitment associating with flexibility and listening seem to suggest that leaders might need flexibility and then listening to the teachers' concerns, for them to get committed in all the three aspects affective, normative and continuance. Therefore, employee well-being and commitment could depend, not only on the physical work context, but also the psychosocial work environment in which inspirational leaders play a key role (Gilbreath \& Benson, 2004; Jabeen et al., 2020). So, staff in organizations, schools in this case, require a more positive attitude and inspiration from their leaders, to get them committed to their job through teamwork (Murphy, 2007).

Moreover, it seems affective and continuance commitment could be predicted better by other aspects, probably emoluments, rather than leaders' traits. So, teachers' feeling of continually working for their schools could be more of the assessment of bearing the cost of leaving the school, rather than leaders' behaviors. Indeed, it was affirmed that continuance commitment may not be desirable, as leaders may expect more than compliance among workers (Cooper, 2003).

Teachers' continuous commitment scores, in particular, were lower, suggesting that teachers had more of an emotional than lower-order transactional attachment to the teaching profession and to their schools. These findings are consistent with results reported elsewhere (Saeed et al., 2013; Clinebell et al.,2013; Omidifar, 2013) and with the assertion that subordinates want leaders who are honest, competent, forward-looking and inspiring (Kouzes \& Posner, 2019; Kouzes \& Posner, 2017).

The finding that normative commitment was associated with all the three traits of leadership also could be traceable in literature. It seems that teachers with strong normative commitment could as well show strong connection to their schools, with feeling of obligation and duty (Meyer \& Allen 1991). Hence, normative commitment appears to encourage teachers to be positive towards work-related behaviors, such as performing the job and work attendance, and in accordance with how leaders inspire them through flexibility, listening, and responsibility (Singh \& Singh, 2019).

Indeed, when leaders are able to meet their leadership obligations, teachers could not only develop affective commitment, but live up to their expectations and organizational demands (Bagraim, 2003). So, an inspirational school leadership environment potentially could arouse a sense of responsibility and a feeling of belongingness among teachers (Bagraim, 2003). The reverse, of course, could be true that a non-inspirational leadership reflects that teachers are not given responsibilities and decision making that will give them the feeling of commitment to the school. The teachers as a result may not feel and accountable and in charge for their schools' success or failure. Nevertheless, the finding that normative commitment was somewhat higher than other components of organizational 
commitment sounds spectacular.

\section{Conclusions and Recommendations}

This study aimed at exploring association between inspirational leadership traits and job commitment among secondary school teachers.

- It is discernable that the three leadership traits of flexibility, listening, and responsibility significantly are associated with normative commitment. Also, the trait of responsibility does not relate significantly to overall commitment, affective, and continuance commitment.

- Close scrutiny of the study results could forecast that inspirational leadership traits serve to motivate teachers to engage in activities, beyond the job requirements, in a way that makes them perform better in their obligations.

- It is recommended, therefore, that head teachers apply the flexibility, listening, and responsibility enable normative commitment of teachers. That way, teachers would develop sense of obligation to the schools, and work continually for better achievement. - Further, we recommend that school administrators be given tailored orientation in inspirational leadership skills. That would enable them encourage teachers to be more committed to the school norms.

\section{Limitations and Implications for Further Research}

Due to the COVID-19 pandemic lockdown at the time of data collection in 2020, the study left out some would-be participants in a couple of schools that were unable to reopen immediately after lifting of the lockdown. It remains unclear, for that reason, what the results would be if teachers in the schools that were left out had been available and considered. Moreover, the study findings have been based on a remote district in the North of Uganda. It is imperative that future studies rollout to more districts in rural and urban settings for comparison purposes. Furthermore, a more sophisticated, mixed approach is recommended for future studies.

\section{Acknowledgements}

The study participants cannot be thanked any better for participating, despite the difficulties they experienced in lieu of the COVID-19 pandemic.

\section{Funding}

This study did not receive funding from the industry, or from any other external sources. 


\section{Conflict of Interest}

The authors declare no competing interests.

\section{Author Contributions}

CRA initiated the study idea and together with AR developed the concept. Further,

CRA and AR developed the study tools. CRA secured ethical clearance, and collected the data, under AR's guidance. CRA and AR analyzed the data and wrote the manuscript. AR prepared the manuscript for submission.

\section{References}

Achua, C. F., \& Lussier, N. R. (2013). Effective leadership 5th international edition. Canada: South Western Cengage Learning.

Alvino, L. (2014). Engaged your employees or lose billions. Forbes Magazine. Retrieved on 22 August, 2021 from http://www.forbes.com/sites/womensmedia/2014/09/29/engage-youremployees-or-lose-billions/

Akinwale, O. E. (2019). Employee voice: speaking up in organization as a correlate of employee productivity in oil and gas industry - an empirical investigation from Nigeria. Serbian Journal of Management, 14(1), 171-195.

Bain. (2017). How to be an Inspirational Leader. Bain \&Company. http://https// www.bain.com \%7Cinsight\%7C how-to-be an Inspirationa-l Leader-infograhic

Bagrain, J. (2003). The dimensionality of professional commitment. SA Journal of Industrial Psychology, 29(2), 6-9.

Banjarnahor, H., Hutabarat, W., Sibuea, A. M., \& Situmorang, M. (2018). Job satisfaction as a mediator between directive and participatory leadership styles toward organizational commitment. International Journal of Instruction, 11(4), 869-888. https://doi.org/10.12973/iji.2018.11455a

Boseman, G. (2008). Effective leadership in a changing world. Journal of Financial Service Professionals, 62, 36-38.

Brown, M., \& Owusu, A. A. (2014). Influence of Head Teachers' Management Styles on Teacher Motivation in Selected Senior High Schools in the Sunyani Municipality of Ghana. International Journal of Learning, Teaching and Educational Research, 4(1).

Bushra, F., Ahmad, U., \& Naveed, A. (2011). Effect of transformational leadership on employees' job satisfaction and organizational commitment in banking sector of Lahore (Pakistan). International Journal of Business and Social Science, 2(18).

Chen, Z.X. and Aryee, S. (2007) Delegation and employee work outcomes: An examination of the cultural context of mediating processes in China. Academy of Management Journal, 50, 226-238. http://dx.doi.org/10.5465/AMJ.2007.24162389

Chib, S. (2016). Study on organizational commitment and workplace empowerment as 
predictors of organization citizenship behaviour. Scholedge International Journal of Management \& Development, 3(3). https://doi.org/10.19085/journal.sijmd030301

Clinebell, S., Skudiene, V., Trijonyte, R., \& Reardon, J. (2013). Impact of leadership styles on employee organizational commitment. Journal of Service Science, 6(1), 139-152.

Cooper, D. J. (2003). Leadership for follower commitment. Elsevier.

Ćulibrk, J., Delić, M., Mitrović, S., \& Ćulibrk, D. (2018). Job satisfaction, organizational commitment and job involvement: The mediating role of job involvement. Frontiers in Psychology, 9, 132.

DeVellis, R. F. (2003). Scale Development: Theory and Applications 3rd Edition. In SAGE publication Ltd.

Duze, C. O. (2012). Leadership styles of principals and job performance of staff in secondary schools in Delta State of Nigeria. An International Journal of Arts and Humanities, 1(2), 224-245.https://doi.org/10.4135/9781452231143

Ellis, S., \& Dick, P.(2003). Introduction to organizational behaviour. London: McGraw Hill.

Fleenor, J. W. (2006). Trait approach to leadership. Encyclopeadia of Industrial and Organizational Psychology.

Fraenkel, J. R., \& Wallen, N. E. (1990). How to design and evaluate research in education. New Jersey : McGraw Hill .

Gilbreath, B., \& Benson, P. G. (2004). The contribution of supervisor behaviour to employee psychological well-being. Work \& Stress, 18(3), 255-266

Goleman, D., \& Boyatzis, R. (2008). Social intelligence and the Biology of leadership the idea in brief the idea in practice. Harvard Business Review, R0809E (September), 8. www.hbr.org

Harris, J.K., \& Kacmar, M.K.(2006). Too much of good thing: the curvilinear effect of leader-member exchange on stress. The Journal of Social Psychology, 146(1), 65-84.

He,J., Zhang, H., \& Morrison, A.M. (2019). The impacts of corperate social responsibility on organisation citizenship behavior and task performance in hospitality. International Journal of Contemporary Hospitality Management, 31, 2582-2598

Huang, G.-h., Zhao, H. H., Niu, X.-y., Ashford, S. J., \& Lee, C. (2014). Reducing job insecurity and increasing performance ratings: Does impression management matter? Journal of Applied Psychology, 99(1), 86. https://doi.org/10.1037/a0035129

Jabeen, A., Zia-Ul-Islam, S., \& Khan, M. A. (2020). Examining principals' leadership styles association with teachers' professional commitment.

Kashagate, R. (2013). Influence of leadership style on teachers' job satisfaction in Tanzania: The case of public secondary schools in Musoma municipal council.

Khan, M. A., Ismail, F. B., Hussain, A., \& Alghazali, B. (2020). The interplay of leadership styles, innovative work behavior, organizational culture, and organizational citizenship behavior. SAGE Open, 10(1), 2158244019898264.

Kiral, E., \& Kacar, O. (2016). The relationship between teachers' school commitment 
and school culture. International Education Studies, 9(12), 90-108.

Kouzes, J. M., \& Posner, B. Z. (2017). A coach's guide to developing exemplary leaders: Making the most of the leadership challenge and the leadership practices inventory (LPI). John Wiley \& Sons.

Kouzes, J., \& Posner, B. (2019). Leadership in higher education: Practices that make a difference. Berrett-Koehler Publishers. Sports Science and Coaching, 13(3), 373-382. https://doi.org/10.1177/1747954117725286

Leithwood, K., \& Sun, J. (2012). The nature and effects of transformational school leadership: A meta-analytic review of unpublished research. Educational Administration Quarterly, 48(3), 387-423.

Malik, A., Aftab, F. Y., \& Ahmad, M. (2018). Job satisfaction and job commitment through transformation leadership. European Journal of Business and Management, 8(October 2016), 55-61.

Maxwell, J. C. (2007). The 21Indispensable qualities of aleader:Becomming the person others will want to follow. Thomas Neslson.

Mercurio, Z. A. (2015). Affective Commitment as a core essence of organizational commitment: An integrative literature review. Human Resource Development Review, 14(4), $389-414$.

Meyer, J. P., \& Allen, N. J. (1990). The measurement and antecedents of affective, continuance and normative commitment to the organization. Journal of Occupational Psychology, 1-18.

Meyer, J. P., \& Allen, N. J. (1991). A three-component conceptualization of organizational commitment. Human Resource Management Review, 1, 61-89.

Meyer, J. P., \& Allen, N. J. (1997a). Advanced topics in organizational behavior series. Commitment in the workplace: Theory, research and application. Sage Publications, Inc.

Meyer, J. P., \& Allen, N. J. (1997b). Commitment in the workplace: Theory, Research and Application. Sage Publications.

Mistry, J., \& Hule, M. A. (2015). Inspirational leadership. Prin. LN Welingkar Institute of Management Development \& Research, 8.

Molenberghs, P., Prochilo, G., Steffens, N. K., Zacher, H., \& Haslam, S. A. (2017). The neuroscience of inspirational leadership: The importance of collective-oriented language and shared group membership. Journal of Management, 43(7), 21682194. https://doi.org/10.1177/0149206314565242

Mueller, C. M., Wallace, J. E., \& Price, J. L. (1992). Employee commitment: Resolving some issues. Work and Occupations, 19(3).

Murphy, S. (2007). The role of emotions and transformational leadership on police culture:an antoethnographic account. Journal of Policescience and Management, 10(2), 165-178.

Mwamatandala, A., \& Muneja, M. S. (2020). Effect of school management on teachers' commitment: A case of government secondary schools in Arusha City, Tanzania. East African Journal of Education and Social Sciences (EAJESS), 1(3), 87-96.

Northhouse, G. P. (2012). Leadership. Sage.

Oduut, \& D. (2017). Government paying-shs-16-billion to absentee teachers. 
https//www.pmldaily.com/news/2017

Omidifar, R. (2013). Leadership style, organizational commitment and job satisfaction: A case study on high school principals in Tehran, Iran. American Journal of Humanities and Social Sciences, 1(4), 263-267.

Oyewobi, L. O., Suleiman, B., \& Muhammad-Jamil, A. (2012). Job satisfaction and job commitment: A study of quantity surveyors in Nigerian public service. International Journal of Business and Management, 7(5). https://doi.org/10.5539/ijbm.v7n5p179

Pangarkar, A., \& Kirkwood, T. (2013, March 14). Four ways to gain employees commitment. Association for Talent Development.

Riivari, E., \& Lämsää, A.M.(2014). Does it pay to be ethical? examining the relationship between organisation's ethical culture and innovations. Journal of Business Ethics, 1, 1-17.

Saeed, S. A. A. A., Gelaidan, H. M., \& Ahmad, F. (2013). New leadership style and lecturers' commitment in Yemen higher education institutions. World Applied Sciences Journal, 21(10), 1460-1467.

Singh, S.K., \& Singh, A.P. (2019). Interplay of organizational justice, psychological empowerment, organisational citizenship behavior, and job satisfaction in the context of circular economy. Management Decision, 57(4), 937 - 952.

Stander, M., \& Rothmann, S. (2009). The relationship between leadership, job satisfaction and organisational commitment. SA Journal of Human Resource Management, 6(3), 7-13. https://doi.org/10.4102/sajhrm.v6i3.145

Susilo, D. (2018). Transformational leadership; A style of motivating employees. Management and Economics Journal (MEC-J), 1, 124. https://doi.org/10.18860/mec-j.v0i1.5222

Wang, Q., Bowling, N. A. (2016). A comparison of general and work-specific personality measures as predictors of organizational citizenship behavior. International Journal of Selection and Assessment, 24(2). https:doi.org/10.1111/ijsa.12139 